ISSN: $2594-4827$

\title{
PESQUISA TRANSLACIONAL EM ENSINO: UMA APROXIMAÇÃO ${ }^{1}$
}

\author{
Irineu Mario Colombo ${ }^{2}$
}

Dirceia Aparecida Silva Anjos ${ }^{3}$

Jovana Ritter Antunes ${ }^{4}$

\section{RESUMO}

A pesquisa translacional teve origem na medicina na década de 1930, sendo que atualmente, o formato é utilizado em várias outras áreas. Na educação, particularmente no ensino de um conteúdo específico, o refinamento da técnica, da didática ou do produto educacional para atingir ao objetivo, deve ser criticado e deve refletir inclusive na revisão do suporte científico e tecnológico adotado para o procedimento de ensino. Este artigo tem o objetivo de apresentar uma aproximação à pesquisa translacional, sua origem e aplicação ao ensino, com base em pesquisa bibliográfica que discute, desde seu uso na área da saúde, até sua transposição para a educação, com apresentação de duas experiências correntes na área de ensino. Ao final, permite considerar que a pesquisa translacional no ensino está em processo de estruturação, discussão e representa uma oportunidade de pensar diferente a forma de ensinar e aprender em ambientes formais e não formais de educação.

Palavras-chave: ensino; pesquisa translacional; produto educacional; pós-modernidade.

\section{ABSTRACT}

Translational research is originated from medicine in the 1930s and the format is used in several other areas now a days. In education, particularly in the teaching of a specific content, the refinement of the technique, didactics or educational product to reach the objective, should be criticized and should reflect even in the revision of the scientific and technological support adopted for the teaching procedure. This article aims to present an approach to translational research, its origin and application to teaching, based on a bibliographical research that discusses, from its use in the health area, to its transposition to education. This article it shows two experiences in action currently, about translational research. In the end, it allows to consider that the translational research in teaching is in the process of structuring, discussion and represents an opportunity to think differently how to teach and learn in formal and non-formal educational places.

Keywords: teaching; translational research; educational product; postmodernity.

\footnotetext{
${ }^{1}$ Este artigo é produto do grupo de pesquisa Educação, Meio Ambiente e Tecnologia (EMAT-IFPR) da linha de pesquisa "Pesquisa translacional em educação profissional e tecnológica".

${ }^{2}$ Instituto Federal do Paraná - IFPR. E-mail: colombo.irineu@gmail.com

${ }^{3}$ Instituto Federal do Paraná - IFPR. E-mail: anjosdirce@gmail.com

${ }^{4}$ Instituto Federal do Paraná - IFPR. E-mail: jovana.antunes@ifpr.edu.br
} 


\section{INTRODUÇÃO}

No documento de 2016 sobre os programas da área de ensino (mestrado e doutorado) a CAPES informa que os doutorados e mestrados desta área focam suas "pesquisas (expressas em artigos, livros e trabalhos em eventos) e produções (expressas em processos, materiais, tecnologias educacionais e sociais, propostas educativas, políticas públicas) em ensino de determinado conteúdo" (CAPES, 2016, p. 2-3, grifo nosso). Para que seja possível este ensino é necessário a integração entre conteúdo disciplinar e conhecimento pedagógico, ou seja, a pedagogia que verifica a melhor forma de apresentar o conteúdo, para que seja apropriado ou ressignificado pelo estudante. Ao pesquisar sobre a questão pedagógica aplicada a determinado conteúdo para fins de ensino, os participantes dos programas devem proceder essencialmente a uma pesquisa translacional.

Num documento anterior a CAPES $^{5}$ aponta que a pesquisa translacional gera "tecnologias, produtos e processos educativos e sociais (...) a partir da aplicação e da mediação do conhecimento acadêmico, retroalimentando-o" (CAPES, 2013, p. 52). Portando ela deve "construir pontes entre conhecimentos acadêmicos gerados em educação e ensino para aplicação em produtos e processos educativos na sociedade" (CAPES, 2013, p. 1 e CAPES, 2016, p. 3).

Embora este artigo tenha como ponto de partida as questões destacadas acima, em que relaciona ensino com pesquisa translacional, faremos, brevemente uma contextualização, com base na literatura, sobre a translação do conhecimento, o surgimento do termo e seu formado. Esta abordagem antecede nossa tentativa de entender o que seja a pesquisa translacional no ensino.

\section{A ORIGEM DA PESQUISA TRANSLACIONAL}

As proposições da translação do conhecimento remontam às ideias de uma discussão pouco conhecida feita na década de 1930, por um médico bacteriologista e imunologista polonês chamado Ludwik Fleck (1896-1961). Neste contexto, esse pesquisador "já apontava a dimensão social, cultural e histórica do processo de construção do conhecimento. Ele identificava os embates e negociações que

\footnotetext{
${ }^{5}$ Acrônimo de Coordenação de Aperfeiçoamento de Pessoal de Nível Superior, que é uma fundação veiculada ao Ministério da Educação, criada em 1951. Entre outras funções, autoriza e supervisiona os programas de mestrado e doutorado no Brasil.
} 
ISSN: $2594-4827$

atravessavam a produção do conhecimento e moldavam seus fatos científicos" (BARBOSA; PEREIRA NETO, 2017, p. 327).

A partir da história da sífilis, o médico polonês passa a criticar a pretensa objetividade e neutralidade da ciência moderna. Para Barbosa e Pereira Neto (2017) o conceito de translação do conhecimento é parte de um novo cenário epistemológico denominado genericamente de ciência pós-moderna, em que há uma reação à soberba do conhecimento científico moderno que invalidava qualquer conhecimento do senso comum (mesmo eficaz), produzindo um conhecimento fragmentado e não aceitando outros saberes. A concepção de uma nova abordagem do conhecimento, de forma translacional, visa a facilitar, incentivar e organizar a troca de diversas formas de conhecimento.

A junção entre o conhecimento científico e o conhecimento fruto da experiência e da vivência no cotidiano possibilita o desenvolvimento da compreensão e do discernimento entre dimensões inicialmente estranhas, que por sua vez, reconfiguram-se gradualmente por meio de interações compartilhadas, que envolvem o próprio conhecimento das ciências, conjunto de métodos e incentivos para aplicação prática e verificar sua reformulação, as ferramentas de aplicação e as lideranças ou coordenações da atividades na parceria sociedade e comunidade científica.

Boaventura Santos (1988, p. 70) afirma que essa nova vertente epistemológica, a ciência pós-moderna, "sabe que nenhuma forma de conhecimento é, em si mesma, racional; só a configuração de todas elas é racional. Tenta, pois, dialogar com outras formas de conhecimento deixando-se penetrar por elas". Esta nova vertente procura restituir ainda o senso comum, antes considerado completamente enganoso, passando a reconhecer algumas virtudes nessa forma de conhecimento que enriquecem a relação do homem com o universo. Neste prisma destaca-se que a translação do conhecimento está consoante com os paradigmas científicos da atualidade, uma vez que transpõe as fronteiras disciplinares e reducionistas do conhecimento e estimula o diálogo entre distintos saberes.

Ao nomear esta nova abordagem do conhecimento científico pós-modernista, Gibbons et al. (1994) chama-a de "Modo 2", em que tende a incorporar um grupo

\footnotetext{
6 Modo 1 é a forma do conhecimento tradicional, gerado de maneira disciplinar num contexto predominantemente hipotético-dedutivo (racionalista) ou hipotético-indutivo (empirista). O Modo 2 é
} 
amplo e heterogêneo de atores e instituições, valorizando a participação da sociedade civil e o conhecimento dos cidadãos, adotando em consequência uma perspectiva científico-social do conhecimento. A aplicação do conhecimento em que envolve o detentor do conhecimento científico e o público, tornam os participantes mais reflexivos, pois

as soluções dos problemas tocam valores e preferência de diferentes indivíduos e grupos tradicionalmente vistos fora do sistema científico e tecnológico. Eles agora podem se tornar agentes ativos na definição e solução de problemas, bem como na avaliação de desempenho (GIBBONS et al., 1994, p. 7, grifo nosso).

Segundo CLAVIER et al. (2011, p. 791) a translação estabelece o nexo entre pesquisa e a prática, que inclui os aspectos: cognitivo (os conteúdos da pesquisa e da ciência); "estratégico (voltado para facilitar o processo de pesquisa e equilibrar relações de poder entre os parceiros) e práticas logísticas (as tarefas práticas de coordenação)”. Portanto a translação não é só sobre o conteúdo, mas também sobre o método, o local, a forma e o incentivo para conhecer.

Para Barbosa e Pereira Neto (2017) a atual definição de translação do conhecimento foi construída a partir de quadros teóricos característicos do final do século XX e início do século XXI. Essa interlocução, de maneira geral, está às voltas com as críticas ao paradigma científico moderno, instituído na revolução científica do século XVI.

A concepção de ciência até o século XVI era tributária do racionalismo hipotético-dedutivo platônico e do empirismo hipotético-indutivo ${ }^{7}$ de Aristóteles. Ambas as abordagens como forma de gerar conhecimento não previam a intervenção no processo (método da experimentação), tinha caráter contemplativo, da observação metódica e conclusões racionalizadas. Não objetivava a intervenção na natureza para seu domínio em prol do homem, através da técnica. A função básica atribuída àquela

gerado no amplo contexto socioeconômico e transdisciplinar (construtivista). (GIBBONS et al., 1994, p. 1).

${ }^{7} \mathrm{O}$ método hipotético-dedutivo partia de um conceito geral, resultado do esforço metódico-racional, o qual seria aplicado a casos particulares; se entendia neste caso que o conhecimento tinha uma única fonte: a racionalidade. $\mathrm{O}$ método hipotético-indutivo, partia da observação ou da experiência sensível reunidas em casos particulares para se chegar um conceito ou conclusão geral; se entendia que a fonte do conhecimento estava na empiria e consequentemente compreendida pela razão (CHAUÍ, 2000). 
ciência era a da explicação do mundo. Um exemplo clássico deste tipo de abordagem era a não permissão de dissecação de corpos humanos para estudá-lo, visto que o corpo morto pertenceria ao divino e era intocável. O saber sobre doenças derivaria ou de um esforço racional (hipotético-dedutivo) ou da observação detalhada (hipotético-indutivo); neste caso o saber obtido era suficiente para entender as causas que faziam as pessoas ficarem doentes e explicar as doenças.

A partir do século XVI, com a maior valorização do ser humano perante os valores clericais, a par do humanismo renascentista, novos conceitos e ideias circulam e nova abordagem científica passa a ser apresentada. $\mathrm{O}$ empirismo intervencionista ganha espaço (Francis Bacon, John Locke e Galileu Galilei), bem como o racionalismo voltado para as questões humanas e com método (Rene Descartes). Na virada do Oitocentos (1700) a ciência moderna começa ganhar um novo estatus, com a experimentação, as padronizações de medidas, a quantificação comparativa, o surgimento de novas disciplinas (mais tarde se tornam ciências autônomas) se separando da filosofia, constituídas por abordagens paradigmáticas, numa cadeia de processos controlados, conceitos e leis referenciadores, entre outros aspectos (CHAUÍ, 2000).

Chegamos à modernidade. A atitude científica passa a dominar a sociedade, tanto que a política e o direito passam a ter status de ciência e a propor soluções quantitativas em oposição às soluções metafísicas ou qualitativas.

Alguns aspectos que relacionamos a este tempo: racionalismo - confiança na capacidade da razão definir, demonstrar e oferecer leis gerais; b) distinção entre sujeito e objeto - a subjetividade produziria o conhecimento verdadeiro (objetivo); c) diferença entre ordem natural e ordem humana; d) o indivíduo como agente livre - capaz de controlar paixões e ações; e) distinção entre o público e o privado - a esfera privada da moral e do mercado; f) ideais revolucionários de civilidade - igualdade, liberdade e fraternidade (direitos civis); g) afirmação do sentido progressivo da história; h) o processo científico como produtor de tecnologias para um futuro melhor, e, i) o progresso social e tecnológico seria próprio dos europeus civilizados (CHAUÍ, 2000 e SANTOS, 1988).

Em suma, a Idade Moderna promove o ambiente de racionalidade científica que pretensamente produzirá continuamente um mundo melhor e superior àqueles que 
tiverem acesso aos seus frutos - técnica e tecnologia. A ideologia da ciência aponta para o progresso e evolução rumo à dominação da natureza, deixando de ser uma explicação da totalidade, mas fundamento para livrar o ser humano dos determinantes naturais. Com isso, a Europa, com esta racionalidade instrumental e com o domínio da tecnologia e da técnica, passa não só a dominar natureza, mas homens e nações. Vem o período do imperialismo, das grandes guerras e do totalitarismo (tanto a esquerda como a direita). Esta crise modernista aparece na virada do Novecentos (1900) (CHAUÍ, 2000 e SANTOS, 1988).

No século XX, as críticas a esta forma de produzir a ciência, bem como a busca de uma nova racionalidade não-apenas-utilitária, passa a defender a superação pósmodernista.

O conjunto de pensamento construído pelos pós-modernos vão na seguinte direção: a) considera ilusória as pretensões de racionalidade em tudo - pois era um disfarce para dominação; b) o conhecimento não é o verdadeiro, mas o útil e eficaz; c) não distingue sujeito do objeto - visto que aquele é quem constrói objetos teóricos e técnicos; d) passa a considerar tanto a ordem natural como a ordem cultural como criações humanas; e) concebe o humano como passional (instintivo, reprimido) - a ética não seria a ação racional para a virtude, mas a satisfação dos desejos de felicidade; f) desconfia da política - consequentemente dando mais importância a aspectos individuais, e, g) dá importância para as diferenças - sendo a sociedade como teia de etnias, gêneros, gostos, etc. (CHAUÍ, 2000 e SANTOS, 1988).

As mudanças em relação a forma de ver a ciência, bem como os conhecimentos filosóficos, éticos, estéticos, culturais e tecnológicos a ela relacionada, confirma a tese de que a mesma não é contínua, pois se a modernidade tinha um modelo, ou seja, um paradigma referencial de validade, a pós-modernidade representará uma tentativa de ruptura deste paradigma.

O filósofo da ciência [Thomas] Khun designa esses momentos de ruptura epistemológica e de criação de novas teorias com a expressão revolução científica, como, por exemplo, a revolução copernicana, que substituiu a explicação geocêntrica pela heliocêntrica. Segundo Khun, um campo científico é criado quando métodos, tecnologias, formas de observação e experimentação, conceitos e demonstrações formam um 
todo sistemático, uma teoria que permite o conhecimento de inúmeros fenômenos. A teoria se torna um modelo de conhecimento ou um paradigma científico (CHAUÍ, 2000, p. 327).

Segundo Barbosa e Pereira Neto é exatamente Thomas Kuhn que apresenta o médico Ludwik Fleck ao mundo, bem como o precoce conceito de translação no conhecimento:

Esse livro de Fleck (1935) [Aspectos epistemológicos da história da reação de Wassermann] era pouco conhecido até que Thomas Kuhn (1998) o mencionou no prefácio de sua obra 'Estrutura das Revoluções Científicas'. Em seu livro, Fleck (2010), colocou em questão o paradigma científico moderno ao apontar os aspectos sociais e históricos que permeiam, moldam e transformam a produção do conhecimento (BARBOSA; PEREIRA NETO, 2017, p. 319).

"O conceito de translação do conhecimento é parte desse novo cenário epistemológico" (BARBOSA; PEREIRA NETO, 2017, p. 319). Coube aos profissionais da saúde, como precursores da pesquisa translacional, apontar uma das formas de reação a fragmentação instrumental da modernidade.

Alguns fatores sociais e culturais contribuíram para que Fleck construísse sua visão sobre o fazer científico. Debruçando-se sobre a história da sífilis, o pensador assinalou que os esforços investigativos e financeiros dispensados ao combate à doença não estiveram ligados tão somente a fatores objetivos ou científicos (BARBOSA; PEREIRA NETO, 2017, p. 320).

A chamada medicina translacional (que incorpora o conceito de pesquisa translacional em toda área da saúde) é “a visão mais emergente da prática médica” e "tem fortes raízes na evolução das ações intervencionistas proporcionadas pela epidemiologia geral ao longo do século passado" (AZEVEDO, 2009, p.81).

Haroldo de Matos colabora com este apontamento, afirmando que a "epidemiologia translacional, entendida como fonte de intervenções populacionais a partir de estudos epidemiológicos" surge quando o médico da rainha Vitória John Snow 
ao investigar a fonte da epidemia de cólera que assolou Londres, entre os anos 1854-1855, apontou para a necessidade de fechar algumas bombas d'água, pois estavam no epicentro de clusters da doença em algumas áreas da cidade. $\mathrm{O}$ trabalho investigativo de Snow, trazendo evidências de que a água era o veículo de transmissão da cólera e a água do rio Tâmisa a fonte da epidemia, foi tão importante que tornou possível a existência das grandes cidades através dos cuidados de saneamento básico (MATOS, 2017, p. 7).

Assim, o retorno do conhecimento dado pela aplicação ou uso prático (do conhecimento posto na realidade) é aceito como determinante para revisão aos erros produzidos pela "certeza" da ciência médica.

A prática e suas contradições são o cerne do conceito do que hoje chama-se pesquisa translacional. Decorre da relação entre a ciência médica, o profissional, a clínica (tecnologia) até chegar na relação personalizada e singular com o doente no sistema de saúde ou na comunidade. Percebe-se ainda que o doente não é passivo, pois reage e interage com atitudes associada à sua peculiaridade cognitiva, psicobiológica e cultural. O processo de tratamento não tem uma única via, o paciente não é passivo. Podemos supor que o doente tem sua forma de viver, alimentar-se, consumir álcool, dormir e praticar exercícios. Ele tem história e conhecimentos. Portanto o processo saúde/doença, para a pesquisa translacional é bidirecional na relação humana, e multidirecional nos demais aspectos (científico, cognitivo, conhecimento tácito, comportamental, do sentido da vida, organizacional, expectativas, estímulos, etc.) (CLAVIER et al., 2011, GIBBONS et al., 1994 e BARBOSA; PEREIRA NETO, 2017).

A maioria dos processos tecnológicos e técnicos é tributária da ciência básica visando a aplicabilidade do conhecimento construído. Na área médica a pesquisa de base é aquela que se dá nas bancadas e laboratórios. Depois percorre um longo caminho até transformar-se em algo tangível na vida das pessoas. Esse caminho, em geral, demora décadas. Segundo Cardoso:

A proposta da Medicina Translacional é, portanto, acelerar esse longo caminho. Representando um recente movimento da comunidade médica internacional, objetiva a estruturação de grupos de pesquisa médica interdisciplinares e 
multidisciplinares, em que naturalmente ocorre a colaboração entre pesquisadores da área básica e aqueles que atuam na área profissional, clínica, cirúrgica ou epidemiológica, todos com foco no desenvolvimento de novas tecnologias aplicadas à Saúde (CARDOSO, 2013, p.2)

Para ser reconhecida como ciência a medicina translacional deve ser calcada em pesquisa (AZEVEDO, 2009), pesquisa com foco multidisciplinar e interdisciplinar, ou seja, cada vez mais específica e ao mesmo tempo abrangente:

Para isso, os pesquisadores translacionais devem estar preparados para unir as descobertas das ciências básicas com o amplo território da investigação clínica e traduzir esses resultados em modificações da prática clínica. [...] Os conceitos envolvidos nessa fase formam a base para a prática baseada em evidências e na criação das diretrizes clínicas. [...] Nesse contexto, a avaliação das terapias, como vemos hoje, é obtida de disciplinas tão diversas como a psicologia, terapia física e nutricional (AZEVEDO, 2009, p. 81).

O conceito nasce com Fleck, porém Reinaldo Guimarães informa que o termo pesquisa translacional nasce nos Estados Unidos, chamada de TR (Translational Research) e "esteve associado a pesquisas realizadas no Instituto Nacional de Câncer, sendo que e apenas na primeira década deste século foi expandida para outros campos de pesquisa em saúde" (GUIMARÃES, 2013, p. 1732). Diz ainda que recentemente a expansão do campo da translação passou a incorporar "aspectos econômicos, sociológicos, jurídicos e éticos" (GUIMARÃES, 2013, p. 1733). Com esta expansão, há uma mudança nos termos: inicialmente era pesquisa translacional, depois passou a se chamar medicina translacional.

A expansão da definição do que era a pesquisa translacional passou a influenciar outras áreas que tinham grandes sistemas de atendimento populacionais como a educação, na busca de resultados mais efetivos e aderentes às necessidades e potencialidades da população.

\section{NA EDUCAÇÃO}


A educação derivada do objetivismo científico modernista influenciou no modelo pedagógico, criando a fragmentação do saber, avançando para a especialização. Santos (1988, p. 64, grifo nosso) destaca este processo na ciência moderna:

Sendo um conhecimento disciplinar, tende a ser um conhecimento disciplinado, isto é, segrega uma organização do saber orientada para policiar as fronteiras entre as disciplinas e reprimir os que as quiserem transpor. É hoje reconhecido que a excessiva parcelização e disciplinarização do saber científico faz do cientista um ignorante especializado e que isso acarreta efeitos negativos. Esses efeitos são sobretudo visíveis no domínio das ciências aplicadas.

O modernismo fragmentou a ciência em disciplinas controladas, tendo uma métrica de sucesso em si, pois fora eficaz para propagação e dominação. A ciência moderna não está tanto para a explicação como para o resultado:

Por este motivo, aceitam a ideologia da competência, isto é, a ideia de que há, na sociedade, os que sabem e os que não sabem, que os primeiros são competentes e têm o direito de mandar e de exercer poderes, enquanto os demais são incompetentes, devendo obedecer e ser mandados. Em resumo, a sociedade deve ser dirigida e comandada pelos que "sabem" e os demais devem executar as tarefas que lhes são ordenadas (CHAUÍ, 2000, p. 358).

A ideologia dominante da modernidade tem na fragmentação do conhecimento um método. Passou a referendar ideologicamente que o conhecimento é melhor obtido e torna-se eficaz se delimitado e com isso a disciplina isolada passou a ser regra escolar e a formação unilateral prevalece. Na Idade Moderna "o método científico assenta na redução da complexidade" delimitada em disciplinas mais apropriadas para quantificar, demonstrar e provar, enquanto que "a fragmentação pós-moderna não é disciplinar e sim temática" com abrangência significativa mais global, sem perder a capacidade de análise (SANTOS, 1988, p. 50;65).

O pós-modernismo passa a criticar o racionalismo instrumental apontando que este tipo de concepção criou dominação, guerras e totalitarismos. A reação pós-moderna será pela formação omnilateral, em que um processo de ensino deve se ocupar da interdisciplinaridade. $\mathrm{O}$ ensino será uma face do processo educacional, em que a prática 
elaborada para tal, somando-se a outras práticas, determinará o todo educacional (CHAUÍ, 2000).

Cabe aqui apontar o entendimento, neste contexto, do que seja educação e ensino:

A Educação é uma prática social e um fenômeno cultural específico, objeto de investigação e estudo interdisciplinar no âmbito das Ciências Humanas, caracterizando-se também como um campo de conhecimento próprio, reconhecido tanto nacional quanto internacionalmente. Esse campo inclui o estudo e a pesquisa das instituições escolares, das atividades educacionais fora da escola, dos sistemas educativos e dos processos sociais e políticos que significam o ato de educar, os saberes educacionais e os sujeitos educativos das mais diferentes formas. Assim, a Educação compreende o ensino, mas o transcende como projeto de formação e, dessa forma, os conteúdos ensinados/aprendidos ganham sentido na interação com as experiências vividas na escola e fora dela (CAPES, 2013b, p. 1).

As diversas ciências modernas, com seu esquadrinhamento bem definido quanto ao método, objeto e finalidade, passam a constituir, invariavelmente as disciplinas escolares, com fronteiras bem demarcadas. A modernidade na educação cria a multidisciplinaridade - a justaposição de disciplinas com pouca relação entre si e, tanto mais é especializada, menos relação terá com outros conhecimentos, até mesmo da mesma área. Surge também a pluridisciplinaridade - tem redução na fragmentação e é composta por disciplinas com relativa sintonia nos domínios do conhecimento.

A pós-modernidade vai conceber uma educação interdisciplinar - em que há interdependência das disciplinas, com sintonia e integração, aproximando de um significado totalizante, e a transdisciplinaridade - a sintonia de diversas disciplinas e conhecimentos não hierárquicos, fluindo entre os saberes tácitos (do senso comum) e os saberes acadêmicos.

$\mathrm{Na}$ busca de superação pós-moderna, as propostas de ensino incorporam a formação educacional omnilateral com a prática do ensino interdisciplinar.

A inter- e a transdisciplinaridade no ensino são requisitos para o sucesso de propostas formativas contemporâneas, no contexto de transição de paradigmas pela qual o mundo passa na atualidade. (...) é o questionamento e a crítica às teorias, conceitos, modelos e soluções 
anteriormente considerados suficientes na resolução de problemas científicos e sociais. (CAPES, 2016, p. 18).

A partir dessas considerações acerca da origem da pesquisa translacional na conjuntura pós-modernista, ficará evidente que a abordagem sobre a educação vai considerar esta nova relação da ciência interagindo com o sistema educacional, o professor e o estudante por um processo de translação no ensino, num modelo inter- e transdisciplinar.

O sistema educacional é aqui entendido como a estrutura legal, administrativa e pedagógica que articula a formação humana, cidadã e produtiva (SAVIANI, 2010). Além disso é compreendido como todos os processos que colaboram para que estes objetivos sejam alcançados fora da educação formal (escolar), seja a educação informal - processo de socialização humana que ocorre durante toda a vida através dos diferentes modos de comunicação, ou não formal - outros processos formativos estruturados em paralelo e com interação ao modelo escolar (museus, escolas de trânsito, teatro, feiras, parques esportivos, etc.).

A pesquisa translacional em ensino, tem como objeto o processo de ensino (também chamado de ensino/aprendizagem), que envolve atores diversos, não somente professores e alunos e a intermediação técnica mais apropriada, com interdisciplinaridade. Portanto, a pesquisa translacional em ensino é uma parte importante da pesquisa em educação.

\section{NO ENSINO}

Como as pesquisas educacionais influenciam a nossa prática em sala de aula? Esse é o mote da pesquisa translacional educacional, articular as diversas áreas do saber para que possam produzir conhecimento aplicável e replicável no chão da escola (MOREIRA, 2018, p. 74).

O conhecimento produzido pelas pesquisas precisa ser acessado e reproduzido pelos organismos educativos. Nada pode ser mais distante de uma sala de aula do que artigos versando sobre temas brilhantes que infelizmente nunca foram testados na prática, sendo fruto de observação empírica porém desvinculados de prática real (DINIZ, 2004). A rapidez com que cresce as investigações nas áreas básicas "e a ausência do seu equivalente nas mesmas proporções de aplicação têm sido objeto de 
preocupação crescente e motivo de ações indutoras em países desenvolvidos" (DINIZ, 2004, p. 273), pois, mesmo na prática clínica médica em setores estratégicos, "a educação avançada e continuada dos atores $^{8}$ precisa se instalar e deverá ficar". Nesta direção Moreira (2018) aponta para onde está indo a atenção da produção da ciência da educação:

Diferentemente da pesquisa básica, dirigida à produção de conhecimentos, a pesquisa aplicada é focada em questões práticas que buscam prover soluções relativamente imediatas. [...] No entanto, essa pesquisa estaria mais perto da produção técnica, por exemplo, de recursos instrucionais como textos de apoio, aplicativos, sequências didáticas, materiais de laboratório. Porém, no contexto acadêmico e na pós-graduação, a produção técnica vale bem menos do que a produção dita intelectual, ou seja, os papers publicados em revistas bem indexadas (MOREIRA, 2018, p. 74, grifo nosso).

Segundo o autor a publicação é muito importante, mas a aplicação efetiva é o que mudará o ensino, aí entra o conceito essencial:

$\mathrm{O}$ termo translacional sugere que resultados de pesquisa existem, estão à mão, mas devem ser traduzidos à linguagem da prática. [...] os resultados dessa pesquisa estão publicados e muitos deles poderiam ser trazidos à sala de aulas, ou seja, transladados à prática ao invés de ficarem restritos à academia. Nessa translação a participação dos professores seria indispensável (MOREIRA, 2018, p. 74-75).

Essa também é a preocupação de Santos, Almeida e Zanotello (2012, p.333):

Entretanto, ainda persistem desafiadoras lacunas entre tais iniciativas e o efetivo uso desses recursos de modo consciente, autônomo, com

\footnotetext{
$8 \mathrm{O}$ termo atores em pesquisa translacional é muito usado, visto indicar não apenas a relação aluno/professor ou médico/paciente, mas todos da cadeia de conhecimento em interação contínua, não hierárquica: pesquisador da ciência básica, pesquisador da tecnologia, gestores dos sistemas, profissionais na relação cotidiana (aplicação técnica) e o usuário. Talvez, por ser translação inverter para romper com qualquer hierarquia: usuários e seus conhecimentos, profissionais do sistema, gestores, pesquisadores, etc. CLAVIER et al. (2012) usam os termos "intermediate actors" e "actor-network theory" do ponto de vista sociológico. Cristovam DINIZ (2004) também usa os termos "comunidades de atores" para especificar segmentos na interação. GIBBONS et al. (1994) trata a estes diferentes personagens na interação de "complex set of actors" com híbridas e peculiares demandas e suportes, com teorias e práticas. Boaventura de Souza SANTOS (1988) trata os atores com a linguagem da filosofia da ciência: "sujeitos individuais ou coletivos" e "autor e sujeito do mundo".
} 
intencionalidade pedagógica definida, que se reflita efetivamente nos processos de ensino e aprendizagem. Parece faltar consonância entre o que se oferece como formação e as necessidades e os anseios dos professores no trabalho diário em sala de aula (grifo nosso).

Algumas experiências dão o tom desta aproximação ao que seja a pesquisa translacional no ensino. Passamos a apresentar alguns exemplos e nossa própria inserção.

Em estudo conduzido por Santos, Almeida e Zanotello (2018), os pesquisadores estavam interessados em verificar a relação entre as $\operatorname{TICs}^{9}$ e a alfabetização científica no Ensino Fundamental I, uma das conclusões foi a efetiva falta de competências e habilidades para não somente lidar com o aparato tecnológico mas entender como as TICs poderiam fazer parte do dia a dia das crianças, durante todo o tempo de permanência na escola e não somente em algum período específico e limitado ao laboratório de informática. A ideia não era mudar os conteúdos, apenas fazer com que novas formas de se relacionar a tecnologia com as demandas de sala fossem encontradas, pois os professores não possuem acesso às pesquisas e às novidades de forma a conseguirem transpor suas limitações pessoais e aplicá-las.

A metodologia utilizada foi a Pesquisa-Ação, com o envolvimento de todos os atores, potencializando a construção reflexiva, que resultou na "construção de saberes associados às relações entre conhecimento tecnológico, pedagógico e das áreas disciplinares" (SANTOS; ALMEIDA; ZANOTELLO, 2018, p. 346).

Nesse sentido já há tempo a CAPES vem implementando uma política voltada para o atendimento dessa demanda. Vejamos o documento da área de ensino de 2016. A área é um desmembramento da grande área multidisciplinar, tendo seu núcleo no ensino de ciência e matemática, por isso sua familiaridade nas pesquisas com as bases desses saberes (CAPES, 2016, p.2), o documento continua discorrendo sobre a necessidade de formação para a junção entre o conteúdo e a prática educativa, foco da atuação das políticas da CAPES para essa vertente do conhecimento são portanto as pesquisas translacionais. “A Área de Ensino é, portanto, uma Área essencialmente de pesquisa translacional, que busca construir pontes entre conhecimentos acadêmicos gerados em

\footnotetext{
${ }^{9}$ TIC - Tecnologias da Informação e Comunicação
} 
educação e ensino, para sua aplicação em produtos e processos educativos na sociedade" (CAPES, 2016, p.3).

A perspectiva interdisciplinar é um pilar da pesquisa translacional, pois a diversidade de pesquisas que podem ser utilizadas em educação (neurociências, psicologia, biotecnologias, TICs, para citar as mais comuns) podem potencialmente promover um grande número de práticas educativas para as diversas fases do ensino/aprendizagem no país. A educação como um todo e principalmente a educação básica onde existe um grande fosso, entre o que é ensinado na graduação e o que é demandado nas escolas, serão beneficiadas com o crescimento e implementação dessas pesquisas.

Cresce cada vez mais a percepção de que a Educação Superior, em nível de graduação, não tem acompanhado a rápida evolução do conhecimento e tem encontrado sérias dificuldades para atender, de maneira satisfatória, a crescente população de ingressantes oriundos da Educação Básica. Por outro lado, e por diversas razões, o contingente de professores da Educação Básica é sabidamente deficitário em termos quantitativos e qualitativos. Assim, um paradoxo tem se materializado nas instituições de ensino superior: o vigoroso crescimento - quantitativo e qualitativo - da produção científica, tida como valor prioritário pela academia nas últimas décadas, acaba por induzir a supervalorização das áreas de conhecimentos específicos, inclusive Educação, e por relegar para segundo plano o foco de integração de conteúdos específicos e pedagógicos (CAPES, 2016, p.12).

Como já exposto no início do artigo, transpor os limites da produção acadêmica é o foco da pesquisa translacional e também uma necessidade do sistema educacional de base brasileiro. Um exemplo dessas políticas são o estímulo aos mestrados profissionais da área que são basicamente endereçados a esse público. Tendo a obrigatoriedade de produzir produtos educacionais juntamente com a dissertação têm sua grande maioria de programas vinculados a instituições de ensino públicas com destaque para os Institutos Federais (CAPES, 2016, p. 6).

Dentro desse contexto o mestrado profissional em Educação Profissional e Tecnológica - ProfEPT, iniciado em 2017, ministrado em rede pelos Institutos Federais 
espalhados pelo território nacional e ligado à grande área do Ensino, pretende contribuir com pesquisas na direção das pesquisas translacionais em ensino. Nosso grupo de pesquisa em Educação, Meio Ambiente e Tecnologia (EMAT), do Câmpus Pinhais do Instituto Federal do Paraná, foi formado em 2014, participam professores e alunas da instituição. Dentro da linha "Pesquisa translacional em educação profissional e tecnológica", temos duas pesquisas, sendo uma delas direcionada à prática educativa em sala, focada no ensino profissionalizante integrado ao ensino médio, e a segunda, voltada para os trabalhadores da educação, focado no processo educativo não formal.

A primeira pesquisa objetiva desenvolver um produto educacional, neste caso, uma sequência didática para alunos do curso técnico em administração, na modalidade integrada ao Ensino Médio. O desafio é que os alunos compreendam e elaborem quesitos e procedimentos para a avaliação de desempenho numa pequena empresa, envolvendo a translação, pois o produto final terá dois tipos de interação prática com o público. A pesquisa abrange definições e teorias sobre o que seja avaliação de desempenho e a ética neste proceder (com base nas ciências da administração e na filosofia da moral), e em seguida a apropriação das tecnologias de procedimentos práticos para tal, ou seja, modelos para proceder na prática a avaliação de desempenho em diversas organizações.

A pesquisa translacional neste caso, com o fim de refinamento da sequência didática tendo como base a teoria e os modelos tecnológicos, fará aflorar a técnica. Mas para a pesquisa ter de fato translação, será aplicado uma avaliação diagnóstica aos alunos para verificar seu entendimento sobre o assunto e ao final da sequência didática a mesma avaliação, mas agora com o fim de comparação da pretensa evolução na abordagem. Outra interação com o público alvo (alunos do curso técnico em administração) é a crítica ou as sugestões que a pesquisadora receberá durante a sequência didática, além de sua própria reflexão sobre pontos e aspectos que poderão ser aprimorados e/ou suprimidos. Com isso, a partir da abordagem científica básica, da apropriação das tecnologias derivadas destas abordagens e por fim a técnica aplicada em sala de aula, resultará num produto educacional, refinado com críticas (aqui com o sentido de julgamento racional, nem positiva e nem negativa), devendo servir para reformular tanto a técnica como repensar aspectos da tecnologia - modelos de avaliação de desempenho apresentados com base na ciência da administração. A perspectiva 
translacional fica evidenciada na junção de diversos conhecimentos aplicados com a finalidade de proporcionar excelência a prática pedagógica, podendo ser replicada imediatamente, após validação, nas salas de aula presenciais ou não.

A segunda pesquisa faz referência à saúde mental dos profissionais envolvidos com o trabalho escolar. Com base em levantamentos bibliográficos pretende-se abordar a relação entre trabalho e saúde mental do servidor público no contexto da educação profissional e tecnológica, identificando fatores que proporcionem prazer ou sofrimento no âmbito do trabalho. Busca conhecer e perceber como o trabalhador em educação encontra-se diante de tais situações no cotidiano de seu trabalho. A premissa teórica do estudo trabalha com a Psicodinâmica do Trabalho de Christophe Dejours (DEJOURS; ABDOUCHELI; JAYET, 1994) e seus colaboradores, a partir da prática vivenciada pelo servidor desse ambiente do serviço público federal. Após a compilação dos materiais identificados busca-se fomentar reflexões sobre o panorama atual em que se encontram as políticas e ações em saúde mental no trabalho no serviço público, seus principais entraves e possibilidades de avanços.

No segundo momento, o produto educacional desenvolvido como fruto da pesquisa acadêmica - um folder educativo, servirá como ação de sensibilização e educação em saúde no espaço de trabalho, propiciando condições para que o servidor assimile informações e orientações sobre a atenção à saúde mental no trabalho, cuidados consigo e os outros, buscando reduzir os agravos à saúde mental e física no ambiente laboral e a geração de um espaço saudável e de valorização da vida capaz de agregar bem-estar, saúde e trabalho.

$\mathrm{O}$ produto educacional nessa pesquisa assume uma identidade didática que se destina à formação/ensino nos ambientes educativos formais e não-formais, integrando diferentes saberes (educação, psicologia, saúde, sociologia, gestão, etc.) e a reconstrução de um conhecimento comum voltado para a compreensão e transformação de uma realidade existente, constituindo-se elemento de grande valor pedagógico. Com relação a aplicabilidade, compreende-se que o folder é um recurso a ser utilizado como uma prática de educação e prevenção em saúde mental no ambiente de trabalho, sendo distribuído de setor a setor na instituição de ensino, criando um espaço de interação e comunicação ainda que indireta com o público-alvo. Os servidores realizarão a avaliação do produto educacional, considerando a exposição do assunto e o atendimento 
aos objetivos da proposta em desenvolver educação e prevenção em saúde mental no trabalho. Na última fase, como resultado advindo desse processo, será feita uma reformulação do material instrucional, na perspectiva da interação ocorrida.

Assim, o presente artigo, ao se valer do conceito de translação do conhecimento, apresenta como principal característica a dinâmica do pesquisador e seu objeto pesquisado, deslocando movimentos, lugares e espaços tradicionais da pesquisa científica e estimulando a troca entre os diversos agentes envolvidos, para então, viabilizar a construção coletiva do conhecimento, capaz de ser aplicado como prática e no processo de tomada de decisão.

O problema que deu origem a estas duas pesquisas ser refere a dificuldade em encontrar referências teóricas e produtos educacionais derivados da prática docente, que explicitasse o fazer translacional incluído, visto que é uma exigência da formação no Mestrado Profissional em Ensino, conforme os documentos da CAPES. As pesquisas estão sendo desenvolvidas no Câmpus Pinhais com apoio do Câmpus Curitiba do IFPR, para oferecer opções bibliográficas e estudos em forma de artigos, especialmente sobre o conceito de pesquisa translacional em ensino, formal ou não formal, para que os próximos estudantes de Mestrado possam avançar a partir desta incipiência.

\section{CONSIDERAÇÕES FINAIS}

A partir de práticas escolares e da necessidade de fundamentar uma nova forma de fazer educação, este artigo é fruto da busca por produções bibliográficas sobre translação em ensino. A aproximação é o esforço destes pesquisadores, a partir do entendimento contemporâneo do termo.

A pesquisa translacional no conhecimento, é a tentativa de superação do viés autoritário de quem sabe sobre os supostos ignorantes. A partir da experiência da medicina translacional, apontou-se para uma melhora na resolução dos problemas de saúde, tanto mais eficaz quanto os atores envolvidos e considerados seus saberes, mobilizados para o conteúdo, para a logística, para o método e para o estímulo. Transposto para a educação, particularmente para o ensino, o conteúdo, bem como o método, deve ser ressignificado e reelaborado com os saberes dos alunos e professores.

Assim, refletir a importância da pesquisa translacional em ensino envolve assumir a tarefa de melhor compreender e desenvolver o seu ideal de construir instrumentos para 
a ação, de produzir vontade, de mobilização e prática de transformação. A noção de translação nos ajuda a lidar com as incertezas do processo, além de colaborar para que a prática pedagógica tenha outros referenciais.

\section{REFERÊNCIAS}

AZEVEDO, Valderilio F. Medicina translacional: qual a importância para a prática reumatológica? Revista Brasileira Reumatol. 49(1), p. 81-83, 2009.

BARBOSA, Letícia; PEREIRA NETO, André. Ludwik Fleck (1896-1961) e a translação do conhecimento: considerações sobre a genealogia de um conceito. Saúde Debate. Rio de Janeiro, v 41, n. esp., p. 317-329, mar. 2017.

CARDOSO, Gilberto Perez. Medicina translacional. Revista conduta médica, n. 56, Abr/Mai/Jun, 2013. Disponível em:

http://www.condutamedica.com.br/artigos.asp?id=98\&mostrarEditorial=S. Acesso em: 14/03/2019.

CAPES. Diretora de Avaliação. Documento de área 2013. Área de avaliação: Ensino. 2013. [S.I.]. Disponível em: www.capes.gov.br/images/stories/download/avaliacaotrienal/Docs_de_area/Ensino_doc _area_e_comissão_block.pdf. Acesso em: 22.09.2018.

. Diretoria de Avaliação. Comunicado conjunto no 001/2013 - Áreas de Ensino e de Educação. Perspectiva de cooperação e articulação. Brasília, 2013 b.

Diretoria de Avaliação. Documento de área 2016. Área de avaliação: Ensino. 2016. [S.I]. Disponível em: www.capes.gov.br/images/documentos/Documentos_de_area_2017/DOCUMENTO_A REA ENSINO 24 MAIO.pdf. Acesso em: 28.09.2018.

Diretoria de Avaliação. Considerações sobre classificação de produção técnica. Área de avaliação: Ensino. 2016. Disponível em: www.capes.gov.br/images/documentos/Classificação_da_Produção_Técnica_2017/46 ENSI_class_prod_tecn_jan2017.pdf. Acesso em: 07/10/2018.

CHAUÍ, Marilena. Convite à Filosofia. Ed. Ática: São Paulo, 2000.

CLAVIER, C. et al. A theory-based model of translation practices in public health participatory research. Sociology of Health \& Illness. Bethesda, v. 34, n. 5, p. 791-805, September, 2011.

DEJOURS, C.; ABDOUCHELI, E.; JAYET, C. Psicodinâmica do trabalho: contribuições da Escola Dejouriana à análise da relação prazer, sofrimento e trabalho. São Paulo: Atlas, 1994. 
DINIZ, C.W.P; Os dilemas do desenvolvimento científico e tecnológico brasileiro. Revista ciência e saúde coletiva, v.9 (2), p. 271 -274, 2004.

GIBBONS, M. et al. The new production of knowledge: the dynamics of science and research in contemporary societies. Sage: Londres, 1994.

GUIMARÃES, R. Pesquisa Translacional: uma interpretação. Revista Ciência \& Saúde Coletiva, v. 18, n. 6. Rio de Janeiro, jun. 2013.

MATOS, H. José de. O quadrante de Pasteur e a pesquisa clínica: por um mundo melhor. Revista Pan-Amazônica de Saúde, v. 8, n. 3, p. 07-08, 2017.

MOREIRA, M. A. Uma análise crítica do ensino de Física. Estudos Avançados 32 (94), p. 73- 80, 2018.

SANTOS, Boaventura de Souza. Um discurso sobre as ciências na transição para uma ciência pós-moderna. Estudos Avançados, São Paulo, v. 2, n. 2, p. 46-71, ago. 1988.

SANTOS, V. G. dos; ALMEIDA, S. E. de; ZANOTELLO, M. A sala de aula como um ambiente equipado tecnologicamente: reflexões sobre formação docente, ensino e aprendizagem nas séries iniciais da educação básica. Rev. Bras. Estudos Pedagógicos, v. 99, n. 252, p. 331-349, 2018.

SAVIANI, Dermeval. Sistema Nacional de Educação articulado ao Plano Nacional de Educação. Revista Brasileira de Educação v. 15 n. 44 maio/ago. 2010. 